\title{
RECONHECIMENTO DO TRABALHO ARTÍSTICO NA SOCIEDADE DE CONSUMO
}

\author{
RECOGNITION OF THE ARTISTIC WORK IN THE CONSUMER SOCIETY
}

Recebido em 14.08.2018. Aprovado em 03.09.2018

Avaliado pelo sistema double blind review

DOI: http://dx.doi.org/10.12712/rpca.v12i3.13184

\section{Monique Nascimento}

moniquenn@gmail.com

Universidade Federal de Santa Catarina (UFSC), Florianópolis/SC, BRASIL

\section{Marina Coelho}

marinacoelho.nina@gmail.com

Universidade Federal de Santa Catarina (UFSC), Florianópolis/SC, BRASIL

\section{Eloise Helena Livramento Dellagnelo}

eloise.livramento@ufsc.br

Universidade Federal de Santa Catarina (UFSC), Florianópolis/SC, BRASIL

\begin{abstract}
Resumo
Propomos refletir, neste estudo, possíveis relações entre consumo cultural e o reconhecimento do trabalho artístico. Para tanto, utilizamos o aporte teórico da psicodinâmica do trabalho e a discussão de Baudrillard (2003) sobre a "A Sociedade de Consumo". Recorremos, como exemplo empírico, ao caso de uma artista atuante na cidade de Florianópolis, observamos o seu cotidiano de trabalho e realizamos quatro entrevistas em profundidade. Defendemos que o trabalho artístico não passa incólume ao processo de homogeneização social, uma vez que a arte se insere na mesma lógica dos demais objetos e é apropriada enquanto bem de consumo. A obra e o fazer artístico guardam, contudo, especificidades que fazem sua inserção na sociedade do consumo produzir consequências nocivas ao artista como trabalhador. Advertimos que o não reconhecimento é nocivo para a subjetividade do trabalhador e a constituição da sua identidade, e influencia de modo significativo na vivência de sofrimento no trabalho.
\end{abstract}

Palavras-chave: Reconhecimento do Trabalho. Sociedade de Consumo. Consumo Cultural. Trabalho Artístico.

\section{Abstract}

We propose to reflect, in this study, possible conections between cultural consumption and the recognition of the artistic work. For this purpose, we use the theoretical contribution of the Psychodynamics of Work and Baudrillard's (2003) discussion on "The Consumer Society". We used, as an empirical example, the case of an artist who works in Florianópolis, we observed her daily work and conducted four in-depth interviews with her. We argue that artistic work does not pass unscathed to the process of social homogenization, in which art is embedded in the same logic of other objects and is appropriate as a consumer good. The work and the artistic keep, however, specific characteristics that its insertion in the consumer society produces harmful consequences to the artist as a worker. We warn that non-recognition is harmful to the subjectivity of the worker and the constitution of his identity, and significantly influences the experience of suffering at work.

Keywords: Recognition of Work. Consumer Society. Cultural Consumption. Psychodynamics of Work. Artistic Work. 


\section{Introdução}

Você jamais compreenderá inteiramente a obra de um homem se não conhecer o próprio homem (Dumas, 2012, p.210).

O excerto, acima destacado, compõe um diálogo entre o maestro Gottlieb e o jovem artista Hoffmann, em uma novela escrita por Alexandre Dumas, intitulada de "A Mulher da Gargantilha de Veludo". Repleta de detalhes na descrição de lugares, objetos e trajes, facilmente o leitor é remetido, por Dumas, às cidades de Mannheim e Paris do século XVIII. O protagonista da novela é o jovem Ernst Theodor Wilhelm Hoffmann, cuja inspiração foi proveniente de um escritor, desenhista e compositor alemão da escola romântica.

No decorrer da obra descrita, o protagonista Hoffmann, motivado pelo desejo de estudar a ópera e música francesa, combina com seu amigo Zacharias Werner, uma viajem à Paris. No entanto, momento antes da viajem, Hoffmann apaixona-se e adia a ida à Paris, para onde Werner segue sozinho. A mulher por quem o jovem artista alemão se apaixona é Antônia, filha do renomado maestro alemão Gottlieb Murr, velho amigo de Werner, a quem este escreve uma carta, recomendando seu jovem amigo.

No instante em que Werner embarca em direção à Paris, Hoffmann bate à porta de Gottlieb, o qual, ao saber da viagem de Werner, comenta das viagens que fez em mocidade, as quais the possibilitaram conhecer aos compositores italianos Giovanni Paisiello e Domenico Cimarosa. Ao ouvir tal comentário, Hoffmann argumenta que o maestro poderia ter acesso às obras de tais compositores, mesmo sem conhecê-los. Eis que Gottlieb, prontamente, faz uma indagação ao jovem artista e consegue expressar em poucas palavras a relevância de se conhecer o saber-fazer e a história do artista para a compreensão de sua obra de arte, bem como de todo o trabalho por ela envolto.

Mas o que é conhecer a obra sem o artista? É conhecer a alma sem o corpo. A obra é o espectro, a aparição, é o que resta de nós após a morte. Mas, note bem, o corpo é o que viveu. Você jamais compreenderá inteiramente a obra de um homem se não conhecer o próprio homem (Dumas, 2012, p.210).
A psicodinâmica do trabalho compartilha desse entendimento. Para a abordagem, cujo principal expoente é o Francês Christophe Dejours, o trabalho realizado por artistas, bem como por outros profissionais, implica em dimensões além das prescritas. Nesse sentido, a avaliação do trabalho por eles desenvolvido, deve envolver julgamentos em que seja considerado, não apenas o trabalho prescrito, mas o trabalho real (DEJOURS, 2012).

Destacamos que, o reconhecimento é considerado, por autores como Gernet e Dejours (2011), uma modalidade particular de julgamento do trabalho que contribui de maneira significativa para a construção do sentido do trabalho. Para a psicodinâmica do trabalho, a formulação de julgamentos - referentes ao reconhecimento do trabalho -, pode ocorrer de duas maneiras: por intermédio da apreciação relativa à utilidade técnica, econômica ou social, sendo formulado pelos superiores hierárquicos, funcionários ou, algumas vezes, pelos clientes; e, por meio da apreciação quanto à beleza do trabalho, sendo proferido por aqueles que conhecem o saber-fazer.

Conforme Gernet e Dejours (2011), o reconhecimento permite a ressignificação do sofrimento em prazer. $\mathrm{Na}$ ausência de reconhecimento, o sofrimento gerado pelo encontro com o trabalho permanece desprovido de significação, e a identidade do sujeito pode ser desestabilizada.

Apesar das discussões relativas à relevância do reconhecimento serem recorrentes no universo do trabalho (DEJOURS, 2012), diferentes exercícios laborais compreendem diferentes dinâmicas de reconhecimento (GERNET; DEJOURS, 2011). Existem profissões de prestígio, valorizadas e reconhecidas, e aquelas não legitimadas socialmente como trabalho ou desvalorizadas. Ainda, trabalhadores cujas atividades não resultam em produtos visíveis, mensuráveis, funcionais e comparáveis caso característico do fazer artístico - tendem a enfrentar dificuldades quanto à dinâmica do reconhecimento.

Segundo Segnini (2008), pesquisas sobre o trabalho artístico fazem parte de um campo de estudos relativamente novo, mas com relevantes contribuições. Destacamos que reconhecer a importância do trabalho para a constituição do sujeito como ser socialmente inscrito, implica em compreender a necessidade do entendimento da dinâmica contemporânea intersubjetiva de seu reconhecimento e as condições sociais e históricas que as envolvem.

Contudo, no Brasil poucas análises foram elaboradas sobre o trabalho do artista (Segnini, 2008). Na obra em que se comemora a prática de 10 anos da Psicodinâmica 
do Trabalho no Brasil, foi realizado o levantamento e análise de pesquisas em Psicodinâmica nas cinco regiões brasileiras - norte, nordeste, centro-oeste, sudeste, sul. Diante do levantamento empreendido, foram apontadas algumas investigações concernentes ao trabalho artístico, provenientes das áreas da psicologia e fisioterapia (MONTEIRO et al., 2017).

Autores brasileiros, como Liliana Segnini $(2010,2014)$ e Pedro Bendassolli (2009), bem como os franceses PierriMichel Menger (2005), Françoise Benhamou (2007) versam a respeito das consequências da lógica concorrencial e da tensão decorrente do binômio artes-negócios no trabalho artístico. No entanto, após revisão sistemática de literatura na base de dados Scopus, não foram encontradas investigações que promovam indagações relativas às implicações do processo de integração da cultura à lógica de consumo - e a diferenciação social que a permeia - no conteúdo dos bens culturais e reconhecimento do trabalho artístico. Nestes termos, justificamos a investigação proposta, a qual visa discutir e analisar as possíveis relações existentes entre o consumo cultural e a dinâmica do reconhecimento do trabalho artístico.

Estruturamos o presente relato de pesquisa em cinco sessões, além do breve esforço de contextualização até aqui empreendido, versamos na sessão seguinte a respeito do consumo cultural e do trabalho artístico na sociedade de consumo, à luz de contribuições de Baudrillard (2003) e de literatura relacionada ao artista enquanto trabalhador; na sequência, abordamos o processo psicodinâmico do reconhecimento do trabalho. $\mathrm{Na}$ quarta sessão apresentamos os procedimentos metodológicos; em seguida discutimos a respeito das possíveis implicações do consumo cultural no processo psicodinâmico do reconhecimento do trabalho artístico com base no caso em estudo; e, por fim, esboçamos algumas reflexões concernentes à proposta desta pesquisa.

\section{Consumo Cultural e 0 Trabalho Artístico na Sociedade de Consumo}

Baudrillard, de maneira semelhante a pensadores como Theodor Adorno, Max Horkheimer e Walter Benjamin, fez do papel da esfera cultural no cotidiano o foco de parte de seus trabalhos. Entre os decênios de 1960 e 1970, o autor debruçou-se sobre o fenômeno da emergência da sociedade de consumo francesa e de uma cultura fundamentada em signos. Em suas obras, Baudrillard desenvolve argumentos referentes ao aparecimento de um novo sistema de valores num mundo capitalista avançado (SANTOS, 2011). No livro intitulado "A Sociedade de Consumo", Jean Baudrillard analisa as sociedades ocidentais contemporâneas, concentrando-se no fenômeno do consumo de objetos.

Para Baudrillard (2003, p. 94), o consumo pode ser compreendido "como um sistema de comunicação e de permuta, como código de signos continuamente emitidos, recebidos e inventados, como linguagem". Como componente de um sistema de valores, o consumo implica na integração e no controle social. $\mathrm{O}$ autor elucida que as sociedades capitalistas não se caracterizam exclusivamente pela produção, mas pelo consumo, dada a manifesta ordem dos signos, em um processo de socialização dos sujeitos à aprendizagem e à iniciação social ao consumo.

Baudrillard (2003) explana que, ao contrário do pensamento amplamente difundido de que se vive em uma nova era, na qual a produção é colocada a serviço da satisfação dos desejos e necessidades do ser humano, o sistema de necessidades é, em realidade, produto do sistema de produção. Nos argumentos iniciais de sua obra, Baudrillard (2003) analisa o tipo diferenciado de relação estabelecida contemporaneamente entre o homem e os objetos que o cercam. Em oposição às sociedades tradicionais, nas quais os objetos eram tomados em sua singularidade, na sociedade de consumo, os objetos são tomados em sua relação estreita com o outro, valendo-se de sua representação, além do valor de utilidade.

Para Baudrillard (2003), vivemos em um ambiente de homogeneização, no qual a cultura - instituída, descoberta e organizada pelo sistema - como objeto de consumo, é integrada e mistura-se à vida cotidiana. A arte insere-se, nesta perspectiva, à mesma lógica de consumo que os demais objetos e é apropriada da mesma maneira, fenômeno que o autor denomina "culturalização da cultura"1. Como bem de consumo, a cultura é absorvida não pelo seu valor de uso, mas pelo valor de troca ou diferenciação social.

Baudrillard (2003) argumenta a perversidade do processo de socialização a que os sujeitos são expostos para tornarem-se consumidores de cultura. Ao invés do "acesso à cultura" estimular uma real democratização, tende a ocorrer, uma pseudoformação, considerando-se que a relação promovida entre os cidadãos e os bens culturais é destituída de uma vivência cultural autêntica.

${ }^{1}$ Ver Baudrillard (2003, p. 18). 
Baudrillard (2003, p. 108) usa o termo "Menor Cultura Comum” (M.C.C.) para designar “a menor panóplia comum de objetos a possuir pelo cidadão médio para aceder ao título de cidadão da sociedade de consumo", e/ou "a menor panóplia de respostas justas que se supõe possuir o indivíduo médio para alcançar a patente de cidadania cultural" - medida da pseudoformação cultural para a inscrição social.

O consumo da cultura "não alimenta [neste sentido] a prática autônoma, mas retórica de mobilidade social": circunstância em que o objeto da cultura, tido como um elemento codificado de estatuto, é consumido por diferenciação social. Opera-se, pois, uma inversão, e o conteúdo genuíno da cultura aparece somente em função e conotação secundária (BAUDRILLARD, 2003, p.112-113).

Baudrillard (2003) observa que, se os bens culturais são vendidos e consumidos, é porque a cultura encontra-se submetida ao modo concorrencial de signos de outros objetos, sendo, por consequência, produzida em função deste. A partir deste pensamento, refletimos as implicações do processo de integração da cultura à lógica de consumo - e da diferenciação social que a permeia - ao conteúdo dos bens culturais e, consequentemente, ao fazer artístico.

Frente a tal perspectiva, ao discutir o significado, o sentido e as tensões no trabalho artístico Bendassolli e Borges-Andrade (2015) ressaltam o caráter conflituoso da relação artes-negócios. A orientação excessivamente comercial, segundo os autores, pode destruir o valor da arte e bloquear a criatividade e um espírito independente, ambos fundamentais para a criação artística. Ademais, a necessidade de adaptação à lógica de consumo pode ser percebida pelos artistas como ausência de autonomia no trabalho (BENDASSOLLI; 2009).

As orientações contraditórias que a esfera artística tem aglutinado, principalmente nos dois últimos séculos, são também destacadas por Menger (2005), como aquelas que envolvem a essência da arte - com os valores simbólicos que a permeiam - e a submissão do trabalho artístico ao atual sistema econômico, que ficam evidentes: na adequação de princípios orientadores do fazer artístico por pressões de eficácia e critérios de aproveitamento; na existência de sistemas de financiamento baseados em mecanismos de mercado; na incorporação da lógica (estrutura, práticas, valores) empresarial por parte das organizações culturais; e, no comportamento simultaneamente, empresarial, individualista e comunitário de seus trabalhadores.

Com base em investigações realizadas no Centro de Sociologia do Trabalho e das Artes sobre a evolução do mercado de trabalho na França, Menger (2001) argumenta que os artistas geralmente apresentam taxas elevadas de auto emprego, variadas formas de subemprego e experimentam uma das maiores desigualdades e variabilidade de renda. Enquanto no mercado de trabalho formal a flexibilidade da contratação geralmente ocorre em funções de fácil substituição, nas artes, a flexibilidade abrange também atividades fortemente qualificadas. A atividade artística implica, neste sentido, na administração dos riscos envolvidos por descontinuidade de trabalhos, perspectivas incertas e remunerações variáveis, conforme retrata Françoise Benhamou (2007).

A descontinuidade, marca evidenciada no trabalho artístico segundo autores como Menger (2001, 2005), Trosby (2001) e Benhamou (2007), decorre da recorrente alternância entre trabalhos, acarretada pela demanda ocasional, oportuna e precária do mercado. Desta descontinuidade derivam as remunerações (e sucesso) variáveis e, de ambas, as perspectivas incertas da carreira artística, também consequência da diferença entre o esforço exigido e o objetivo a ser alcançado e do caráter temporário do sucesso, o qual está sujeito às modas que o mundo das artes alimenta (THORSBY, 2001; BENHAMOU, 2007). Segundo Menger (2005), a incerteza do sucesso e de remuneração, ao mesmo tempo em que contribui para o prestígio social das profissões artísticas, gera disparidades entre aqueles que, numa espécie de loteria, obtém reconhecimento e os que são relegados aos mais baixos níveis de notoriedade.

Percebemos, assim, um encadeamento que configura uma dinâmica conflituosa e nociva na atividade artística provocada pelo sistema de mercado e pelo consumo cultural por ele determinado, a qual influencia o processo psicodinâmico do reconhecimento da arte enquanto trabalho e afeta a subjetividade destes trabalhadores.

\section{O Processo Psicodinâmico do Reconhecimento}

Para a abordagem cujo principal expoente é o francês Christophe Dejours, "o trabalho é aquilo que implica, do ponto de vista humano, o fato de trabalhar: gestos, saber-fazer, um engajamento do corpo, a mobilização da inteligência, a capacidade de refletir, de interpretar e de reagir às situações; é o poder de sentir, de pensar, de inventar" (DEJOURS, 2012, p.24). Nesse sentido, o trabalho não é considerado, em primeira instância, relação salarial ou emprego, mas sim uma maneira de engajamento da personalidade para responder a uma tarefa delimitada por pressões, que podem ser materiais ou sociais (DEJOURS, 2004b, 2012). 
Desse modo, compreendemos que o trabalhar vai além de uma simples execução de tarefas. O trabalhar é ação e mobilização subjetiva (FACAS et al., 2013) frente ao real do trabalho, de maneira a conduzir o sujeito a pensar e agir de forma diferente do que foi prescrito pela organização do trabalho. A mobilização subjetiva, além da articulação dos desejos, compreende os gestos e o engajamento do corpo, que mobilizam uma inteligência em ação. Tal inteligência é ligada à ideia de astúcia, que utiliza de sua capacidade inventiva para criar novos saber-fazer, transgredindo o trabalho prescrito, e mobiliza-se a partir de situações imprevistas (DEJOURS, 2012).

Por ser uma inteligência ancorada no corpo, a inteligência prática necessita de um espaço público de fala e de discussão para conquistar visibilidade e reconhecimento. O espaço público de discussão é considerado como um espaço à fala constituído pelos trabalhadores para auto expressão, autenticidade e relação de equidade entre aquele que fala e aquele que escuta (MENDES, 2007). Quando há a manutenção do espaço público de discussão, viabilizase a construção de relações baseadas na confiança e na cooperação entre os pares, constituindo, dessa forma, um espaço onde o trabalhador pode repensar seu trabalho ao falar sobre ele, interpretá-lo, e modificá-lo para que possa transformar situações adoecedoras (MERLO et al., 2013).

Ao se impossibilitar o estabelecimento de um espaço público de discussão, pode-se inviabilizar não somente a legitimação da inteligência prática, mas também a cooperação e o reconhecimento, situações que permitem a percepção da relação de imbricamento existente entre inteligência prática, espaço público de discussão, cooperação e a dinâmica intersubjetiva do reconhecimento. Antes de adentrar nas especificidades desta dinâmica, cabe versar acerca do entendimento dejouriano de reconhecimento no trabalho. A concepção de reconhecimento em psicodinâmica do trabalho sustenta-se na contribuição do antropólogo do trabalho, François Sigaut, no tocante ao laço entre técnica, identidade e reconhecimento pelo outro (GERNET; DEJOURS, 2011).

Segundo Dejours (2012), o reconhecimento no trabalho é uma forma de retribuição simbólica, proferida por atores engajados na organização, pelos esforços e contribuições do sujeito ao realizar aquilo que the foi designado. Tal retribuição, é capaz de oferecer uma gratificação ao sujeito em relação às suas expectativas, face à realização de si mesmo. Nessa acepção, conforme o autor, o reconhecimento é caracterizado por um processo dinâmico e intersubjetivo, que pode ser compreendido a partir de duas dimensões, a saber: reconhecimento no sentido de constatação, conhecimento e/ou revelação do real do trabalho, e da contribuição que o sujeito oferece à organização, a partir do real; e, reconhecimento no sentido de gratidão pela contribuição dos trabalhadores no ajustamento da organização do trabalho.

Cabe destacar que na perspectiva dejouriana, o reconhecimento não é simples gratificação, e para ter eficiência simbólica, passa por julgamentos. O julgamento por sua vez, assume duas formas: o julgamento da beleza e o julgamento da utilidade (LIMA, 2013; DEJOURS, 2012). O julgamento de utilidade diz respeito à utilidade econômica, técnica e/ou social do trabalho realizado (de maneira singular e coletiva), conferindo ao trabalhador sua afirmação na esfera do trabalho. Nesse julgamento, é proferida uma avaliação sobre o trabalho efetuado, sobretudo, verticalmente por superiores hierárquicos e, eventualmente, por clientes (LIMA, 2013; DEJOURS, 2012).

A apreciação quanto à beleza, que diz respeito à qualidade do trabalho, é expressa, sobretudo, em termos principalmente estéticos (DEJOURS, 2012) e é proferida, geralmente, pela linha horizontal (LIMA, 2013). Este julgamento só pode ser proferido por aqueles que conhecem a fundo o trabalho. Ele credencia um retorno de pertencimento a um coletivo (DEJOURS, 2012), pode possibilitar o reconhecimento de uma identidade singular (LIMA, 2013) e decompõese em dois níveis, a saber: julgamento da conformidade e julgamento da originalidade (LIMA, 2013).

O julgamento da conformidade, como um dos níveis do julgamento da beleza, é um julgamento muito mais severo e exigente do que o julgamento da utilidade, tendo em vista que não é proferido por hierarquias ou clientes, mas sim por aqueles que conhecem a fundo o trabalho realizado, os pares. Nesse sentido, quem julga se o trabalho de um artista apresenta todas as qualidades implicadas "às normas da arte" é outro artista. Assim, o sujeito é reconhecido como possuidor das qualidades e saber-fazer, assim como daqueles que constituem o coletivo de trabalho, equipe ou comunidade de pertença (LIMA, 2013).

Para que se tenha acesso ao segundo nível do julgamento da beleza de um trabalho, é necessário possuir o primeiro. $\mathrm{O}$ segundo nível, diz respeito ao julgamento da originalidade, trata-se de ir além das qualidades comuns. Nesse julgamento, a originalidade é reconhecida. O julgamento é proferido em termos estéticos "é uma bela obra de arte". Há aqui um julgamento tão preciso, que é possível reconhecer o seu autor pela observação de seu trabalho (LIMA, 2013).

Dessa forma, o reconhecimento foca o fazer e só em um segundo momento o sujeito pode repatriar esse julgamento 
do registro do fazer para o registro do ser. O reconhecimento, enquanto simbólico e possibilitador da ressignificação do sofrimento em prazer, trata-se da identidade que deseja realizar-se. Justamente porque o trabalho pode possibilitar gratificações essenciais no registro da identidade, é que se pode alcançar a mobilização subjetiva, a inteligência e o zelo dos que trabalham (DEJOURS, 2012).

Para a psicodinâmica do trabalho, a saúde no trabalho é uma construção mediada pela dinâmica intersubjetiva do reconhecimento, a qual ao conferir julgamento de utilidade, de beleza ao trabalho, possibilita a construção da identidade do trabalhador, considerada central para a busca de equilíbrio psíquico (DEJOURS, 2012). Quando ocorre o funcionamento da dinâmica do reconhecimento, o resultado do trabalho repercute em favor da autorrealização e da construção da identidade do sujeito. Caso contrário, se não há o reconhecimento, o sofrimento acaba não sendo ressignificado em prazer e o trabalho perde então seu sentido subjetivo, possibilitando o aparecimento da crise de identidade e de outras patologias (DEJOURS, 2012).

Com intuito de se possibilitar uma maior compreensão do trabalho como estruturante psíquico e como lugar de prazer, apresentaremos, a seguir, articulações entre a dinâmica do reconhecimento e do prazer na perspectiva da psicodinâmica do trabalho e algumas ideias de Sigmund Freud, principalmente relacionadas à teoria da pulsão e da sublimação.

Para Freud ([1930]2011), o trabalho pode ser tanto fonte de prazer quanto de sofrimento. Como um dos caminhos para a felicidade, o trabalho permite a operação de um dos mais evoluídos mecanismos psíquicos, o processo de sublimação. Por meio da sublimação torna-se possível a vivência do prazer no trabalho, tendo em vista que a pulsão é ressignificada em gratificação social. Nas palavras de Mendes (2011, p. 16), "a sublimação pressupõe que o prazer sexual foi ressignificado. Esse prazer mantémse na sua essência, mas o alvo e o objetivo são outros, sendo a gratificação não mais erótica, mas social." Nessa perspectiva, o prazer é a pulsão ressignificada, simbolizada, com alvos e objetos definidos, e socialmente valorizados.

De modo oposto às defesas, as quais se manifestam em sintomas variados e que podem se constituir em patologias, a sublimação é intrinsecamente relacionada ao prazer. O prazer implica na busca de satisfação de desejos apresentados pelo sujeito, podendo ser considerado uma manifestação ocasional, tendo vista as contraposições impostas pela civilização (FREUD, [1930]2011). No trabalho, o prazer, no sentido de gratificação pulsional, pode ser associado à sublimação que não gera uma descarga pulsional direta, mas que não se distancia muito dela nos resultados de satisfação. Mendes (2011) refere que o prazer também pode ser a liberdade de escolha, que pressupõe que o sujeito se aproprie, de modo consciente, de sua história de vida e do contexto em que as relações de trabalho se estabelecem.

Assim, podemos concluir que o prazer, vivenciado de maneira direta pela sublimação ou indireta pela ressignificação do sofrimento é fundamental para a estruturação psíquica do sujeito trabalhador, tendo em vista, que permite a atuação de processos sublimatórios responsáveis pela gratificação das pulsões - dimensão considerada central para a construção da saúde e da subjetividade (MENDES, 2011). Dejours (2012) aponta a dinâmica do reconhecimento como favorável à sublimação e como uma possibilidade de o trabalhador vivenciar prazer e de ressignificar situações sofríveis.

Todavia, Dejours (2012) elucida que a sublimação, na dinâmica do reconhecimento, não se limita a um processo solipsista e puramente intrapsíquico, havendo, assim, um teatro social próprio à sublimação. Destarte, para que se possa refletir a respeito da prática de reconhecimento, necessita-se resgatar a sua dimensão sócio histórica, compreendendo a historicidade, as relações sociais e de poder envolvidas no contexto de trabalho (MARTINS; LIMA, 2015).

Diante de tal perspectiva, ressaltamos a relevância da realização de reflexões acerca das implicações do processo de integração da cultura à lógica de consumo (e da diferenciação social que a permeia) ao conteúdo dos bens culturais e, consequentemente, ao fazer artístico e a subjetividade do artista enquanto trabalhador.

Realizadas as discussões acerca do consumo cultural, do trabalho artístico na sociedade de consumo e do processo psicodinâmico do reconhecimento, descrevemos, a seguir, os procedimentos metodológicos realizados nesta pesquisa.

\section{Procedimentos Metodológicos}

Realizamos um estudo de caso do tipo instrumental como exemplo ilustrativo da reflexão proposta e linha argumentativa desenvolvida. Utilizamos métodos qualitativos para coleta dos dados. Compreendemos que a investigação do caso específico poderia fornecer insights e facilitar o entendimento mais amplo da dinâmica do reconhecimento do trabalho artístico na sociedade contemporânea caracterizada pelo consumo, 
contribuindo para contestar a generalização meritocrática de reconhecimento, amplamente aceita.

Haja vista a complexidade concernente à organização e à definição dos setores denominados criativos e culturais, David Throsby (2001b) elaborou um modelo que categoriza as atividades relacionadas a tais setores em três círculos concêntricos. No núcleo do modelo encontramse as artes criativas tradicionalmente conhecidas como: artes visuais; literatura; patrimônio cultural; música; dança; artesanato; artes performáticas; e práticas que envolvem o uso de tecnologia (arte multimídia). Para FGV (2015), a economia da cultura corresponde a setores tipicamente conectados à produção artístico-cultural, a saber: música; dança; teatro; artes visuais; literatura; patrimônio cultural e circo. Assim, estabelecemos como critério para a escolha da artista participante desta pesquisa a atuação em pelo menos uma das áreas do setor cultural que estivesse em consonância com aquelas abrangidas pela delimitação de economia da cultura, realizada pela Fundação Getúlio Vargas (2015) e com núcleo do modelo composto de três círculos concêntricos proposto por Throsby (2001).

Outro pressuposto para a seleção da artista foi a satisfação de ao menos dois aspectos evidenciados por David Throsby (2001), como relevantes para se considerar um sujeito enquanto artista profissional, sendo eles: demonstrar evidência de aceitação pelos pares; possuir qualificações educacionais adequadas e/ou ter um conjunto suficiente de experiência em atividades artísticas ao invés de treinamento formal; dedicar uma quantidade mínima de tempo no trabalho criativo durante um período determinado; pertencer a um organismo de certificação; e ganhar certo nível de rendimentos advindo do trabalho artístico.

Quatro sujeitos participaram da primeira seleção e foram protagonistas de um estudo relacionado às vivências de prazer e sofrimento no trabalho artístico. Após a realização de tal estudo, optamos pelo caso da entrevistada, a Equilibrista, para a investigação aqui proposta, tendo em vista que sua história e trajetória profissional podem contribuir para compreensão da relação entre o consumo cultural e a dinâmica do reconhecimento do trabalho artístico. No momento da investigação, Equilibrista possuía vinte e seis anos de idade, aproximadamente vinte anos de vivências na área da dança e trabalhava há cinco anos exclusivamente como artista.

Realizamos observações de sua rotina de trabalho e quatro entrevistas semiestruturadas individuais em profundidade (com duração aproximada de uma hora cada), entre os meses de setembro a 2016 e junho de 2017. No primeiro contato com a artista o sigilo em relação a sua identificação foi reforçado, o termo de consentimento livre e esclarecido foi explicado e assinado. Observamos o cotidiano laboral, conforme a disponibilidade da artista e também acompanhamos apresentações abertas ao público. Registramos os dados por meio de gravações, fotografias e diário de campo.

Orientamos as entrevistas por questões amplas que possibilitaram a escuta das mais variadas vivências da trabalhadora relacionadas com o objetivo da pesquisa, como: Conte-me sobre sua história de vida e trajetória profissional; Conte-me sobre seu trabalho como artista; Você sente que seu trabalho é reconhecido?; O que lhe dá prazer no trabalho; O que você faz para lidar com as dificuldades diárias de seu trabalho como artista.

O conteúdo das entrevistas foi analisado a partir de categorias definidas a priori - julgamento da beleza e julgamento da utilidade - com base no método de análise de conteúdo, desenvolvido por Bardin (2016). Posteriormente, os dados provenientes da análise de conteúdo e das observações foram analisados à luz do arcabouço teórico da Psicodinâmica do Trabalho, de discussões empreendidas por Baudrillard (2003) e da literatura relacionada ao trabalho artístico.

\section{Discussões e Análise}

Descrevemos brevemente, neste tópico, aspectos das vivências do trabalho real narrados por Equilibrista e discutimos, a partir deles, a questão do reconhecimento do trabalho artístico na sociedade de consumo e suas implicações para a subjetividade do artista. Salientamos que o nome Equilibrista foi o pseudônimo escolhido pela artista para preservar sua identidade.

\section{O Caso de Equilibrista}

Equilibrista possuía vinte e seis anos de idade, nasceu em Florianópolis, Santa Catarina e, à época da pesquisa, residia com seus pais e namorado, em sua cidade natal. Coreógrafa, bailarina, professora de dança e graduanda em arquitetura, inseriu-se no campo da cultura e das artes em 1996, quando tinha cinco anos de idade. Com o repertório de onze anos de aulas em ballet clássico, oito anos em danças urbanas e inúmeras participações em eventos, espetáculos e festivais de dança, Equilibrista iniciou, no ano de 2012, sua carreira como professora de dança.

À época da pesquisa, a artista dirigia uma companhia de danças urbanas, era voluntária em um grupo de danças 
urbanas infanto-juvenil em um projeto social e também trabalhava como professora de dança em uma escola de dança e em uma escola privada de ensino fundamental e infantil de período integral. Além do rendimento proveniente de seu trabalho enquanto professora de dança, a realização de espetáculos, contratações de apresentações por organizações e premiações relativas a eventos de dança, complementavam o orçamento de Equilibrista.

Apreendemos dos relatos de Equilibrista que suas vivências de trabalho são fortemente marcadas por um contexto de: ausência de vínculos formais de trabalho; atuação em atividades ou projetos temporários, informais, simultâneos com diferentes clientes; variabilidade de renda; ritmo de trabalho intenso; forte cobrança de ordem pessoal, por resultados financeiros e pelo desempenho de seu corpo e por possuir uma fronteira porosa entre vida pessoal e trabalho.

Equilibrista fala do prazer em seu trabalho, estabelecendo relações com: o exercício da profissão de livre escolha; os momentos durante e pós-apresentação; a possibilidade de ensinar, aprender com seus alunos, e acompanhar a evolução dos mesmos na dança; o processo de criação; liberdade para criar - incluindo: o desenvolvimento de atividades condução das aulas de dança; a escolha de músicas; o desenvolvimento de coreografias, figurinos e cenário -; as experiências exitosas diante de circunstâncias imprevistas; e, o reconhecimento pelo trabalho desenvolvido, especialmente quando proveniente dos pares.

As vivências de sofrimento relacionadas ao exercício artístico estão relacionadas em seu relato:à não compreensão do fazer artístico como um trabalho por parte da sociedade em geral; à ausência de vínculos formais de trabalho e benefícios trabalhistas a eles associados; à inseguranças financeiras; ao ritmo de trabalho intenso; à restrição da liberdade para criar - incluindo-se: desenvolvimento de atividades condução das aulas de dança; escolha de músicas; desenvolvimento de coreografias, figurinos e cenário. -; à falta de reconhecimento do trabalho desenvolvido, proveniente de outros artistas da dança.

Destacamos, uma vez mais, que o reconhecimento do trabalho marca o relato da artista tanto em referência às vivências de prazer quanto de sofrimento - neste caso pela ausência.

\section{O Reconhecimento do Trabalho Artístico na Sociedade do Consumo}

A partir da análise das vivências relatadas nas entrevistas, observamos um imbricamento entre inteligência prática, espaço público de discussão, cooperação e a dinâmica intersubjetiva do reconhecimento. Optamos, pois, antes de adentrar às especificidades da dinâmica da relação consumo cultural/reconhecimento, apresentar e discutir alguns resultados acerca destas categorias relativas à mobilização subjetiva da artista, ainda que de forma breve.

Os estudos em psicodinâmica pressupõem que a mobilização subjetiva emerge das exigências e constrangimentos da organização, e demanda uma forma de inteligência, a prática, a qual envolve um investimento corporal, afetivo e cognitivo, como forma de ajustamento criativo à prescrição e transgressão à organização do trabalho - os sujeitos experimentam, assim, (indo além do prescrito) o real do trabalho (DEJOURS, 2012; MENDES; DUARTE, 2013; VASCONCELOS, 2013).

Enquanto dançarina, Equilibrista discorre que frequentemente ocorrem imprevistos, de ordem técnica (música, iluminação, cenário) ou relacionados à execução das coreografias em apresentações e participações em eventos de dança. A artista relata que o esquecimento momentâneo de parte de coreografias é algo comum entre dançarinos e elucida que contornar essa situação, de modo a minimizar ou evitar a percepção de algo diferente do esperado e/ou de erros, por parte do público, exige técnica e amadurecimento profissional (inteligência prática): "Em eventos mais formais que têm coreografia pronta, acontece às vezes de dar um branco. Isso é uma coisa de saber lidar e não deixar gerar muito desconforto. (...). Isso é questão de amadurecimento. Quanto mais tu vais passando, mais tu vais aprendendo" (Equilibrista).

Além do uso da inteligência prática, percebemos a existência de espaços de discussão das atividades e de relações de cooperação no cotidiano da dançarina. A artista relata que na escola de dança em que trabalha como professora, diferentemente dos demais locais em que atua, há uma melhor relação interpessoal, aspecto facilitado pela existência destes espaços de discussão. De acordo com Equilibrista, os professores da escola de dança reúnemse com a direção da escola com certa frequência para discutirem questões relativas à execução de atividades na rotina de trabalho e eventos a serem realizados.

Lembramos, no entanto, que para a psicodinâmica, o espaço público de discussão é constituído pelos trabalhadores para auto expressão, autenticidade e relação de equidade entre aquele que fala e aquele que escuta (MENDES, 2007). Assim, consideramos que os espaços para deliberações e decisões relativas à execução do trabalho, relatados pela dançarina, não configuram, nesta perspectiva, espaços públicos de discussão em que Equilibrista, enquanto trabalhadora, pudesse repensar seu trabalho ao falar sobre ele, interpretá-lo e modificá-lo na busca da ressignificação de 
situações sofríveis. Salientamos que o não estabelecimento de espaços públicos de discussão pode ser deletério à saúde dos trabalhadores por inviabilizar não apenas a subversão do sofrimento em prazer por meio da utilização desse elemento da categoria mobilização subjetiva, mas também dos elementos cooperação e reconhecimento a ele relacionados.

As relações de cooperação no trabalho de Equilibrista ocorrem de maneira variada. Enquanto dançarina e dirigente de uma companhia de danças urbanas, notamos que, de maneira geral, a cooperação se faz presente, sendo observada através da admiração mútua entre dirigentes e integrantes dos grupos de dança, ao se reconhecerem como dançarinos competentes. Todavia, como professora de dança, ressaltamos que as relações de cooperação com outros colegas de trabalho, ocorrem de maneira limitada. De acordo com Equilibrista, a convivência conflituosa entre artistas de sua área de atuação na esfera artística, pode ser potencializada pela competitividade provocada por concursos/eventos de competição, os quais são bastante frequentes na área da dança.

Corrobora com a percepção de Equilibrista, o sociólogo francês Pierre-Michel Mendes (2005), ao apontar que o setor artístico estabelece uma reunião ímpar entre o comunitarismo e o individualismo. Para o autor, a busca sistemática por originalidade estética e reconhecimento tende a resultar em um individualismo exacerbado entre tal categoria de trabalhadores. Dessa maneira, compreendemos que embora mantenham-se laços de cooperação entre membros de um mesmo grupo, a busca por reconhecimento tende a influenciar na perpetuação de um comportamento individualista, especialmente (mas não só) entre diferentes grupos de artistas.

A não cooperação entre grupos de dança relatada por Equilibrista faz sentido quando lembramos que a cooperação repousa (implica, pois) na base coletiva, na intenção de trabalho conjunto e construção de uma obra comum (SANT'ANNA, 2013; DEJOURS, 2012; MENDES, 2007). Ainda, caracteriza-se pela convergência das contribuições de cada trabalhador e nas relações de convivência e interdependência (articulação de talentos específicos, integração das diferenças individuais) (MENDES, 2007; DEJOURS, 2012) - condições que diferem da dinâmica de relação entre grupos.

Nas situações em que o reconhecimento do trabalho de Equilibrista pôde ser vivenciado, a partir do julgamento da beleza, foi possível perceber a existência de relações de cooperação, maior facilidade para a manutenção de um espaço de discussão, bem como a legitimação de ações concernentes ao uso da inteligência prática, entre Equilibrista e seus pares. Circunstância, que está em consonância com a relação estabelecida por Dejours (2012b) entre cooperação e reconhecimento por intermédio do julgamento da beleza de um trabalho. Dejours (2012b) discorre que o reconhecimento dos pares sobre o fazer, possibilita o respeito e a manutenção de relações de cooperação entre os sujeitos, inclusive entre aqueles que não se tem empatia ou se sente algum tipo de aversão.

Nas atividades em que a cooperação se fez presente, a mesma pôde ser observada através da admiração mútua entre os artistas, ao se reconhecerem como profissionais competentes da dança Além do reconhecimento existente entre tais artistas, foi possível observar a existência de uma intensa troca de saberes durante o processo de trabalho, assim como de apoio e de um espaço para conversas sobre a melhor maneira de executar seu trabalho.

Na medida em que a manutenção de relações de cooperação entre os pares oportuniza o julgamento da beleza, a tensão decorrente do ambiente de competições, assim como a busca por espaço e destaque em eventos, dificulta o reconhecimento por meio desta forma de apreciação do trabalho artístico. Acreditamos que tal situação ocorra ao se tolher a existência de relações de cooperação e a manutenção de espaços públicos de discussão, bem como por dificultar a legitimação de ações referentes ao uso da inteligência prática entre artistas de diferentes grupos.

A lógica concorrencial que existe nos eventos de dança e o modelo de avaliação padronizado tende, assim, a inibir o reconhecimento entre os pares. Conforme Equilibrista, grupos cujas apresentações não se adequam a tais padrões são mal avaliados e perdem reconhecimento no campo. De acordo com a artista:

A gente percebe muito que tem festivais e
festivais. Tem festivais, que na verdade são a
grande maioria, que seguem um padrão mais
comercial da dança. Então (...) se cria um
padrão da dança. (...). Ai quando a gente
vem com uma coisa e tal, com uma proposta
um pouco diferente do que é aquele padrão
que usa várias músicas mais frenéticas, (...)
a gente acaba não alcançando os objetivos
que a gente gostaria de alcançar. Por
exemplo: de conseguirpremiaçõos nos festivais
(Equilibrista).

Diante dos fatos apresentados, Equilibrista relata que enfrenta sistematicamente o conflito entre a decisão de criar 
gozando de total liberdade, inclusive, com a possibilidade de manifestar seus posicionamentos sociais e políticos e a decisão estratégica de montar uma sequência técnica de movimentos que atenda ao rigor dos critérios padronizados de avaliações de festivais/concursos, no intuito de alcançar reconhecimento. Nas palavras da artista:

Várias vezes a gente já se colocou um pouco nessa duivida. (...). Se a gente continua fazendo as coreografias, sobre o que a gente acredita ou a gente se encaixa no padrão para conseguir atingir um nivel de premiaçôes, para ficar mais conhecidos. Porque querendo on não o festival tem muito esse papel, da porta, e ser a janela. (...). Ai a gente fica sempre nessa coisa, o que que eu faço?! Eu sigo esse meu ideal e com a minha liberdade de criar, ou eu me encaixo no padrão para ganhar algum reconbecimento? (Equilibrista).

A situação descrita por Equilibrista reforça a observação de Baudrilard (2003) sobre a submissão contemporânea da cultura à mesma lógica concorrencial de signos que outros objetos, e sua consequente produção em função dela. Para Baudrillard (2003), a cultura não foge ao movimento de homogeneização generalizado - a arte insere-se na mesma lógica de consumo dos demais objetos de mercado.

Equilibrista mostra ciência de que adequar-se aos critérios dos festivais e eventos de dança, influencia não apenas em sua posição na avaliação comparativa com os seus pares e obtenção de uma possível premiação, mas também na perspectiva de reconhecimento proveniente de outros profissionais da dança. Em tal circunstância, podemos observar a atuação do ethos competitivo do modo de produção capitalista no julgamento da beleza do trabalho desenvolvido, na medida em que ocorre uma inibição desta forma de julgamento.

Convém considerar os trabalhos de Lima (2009) e Alvarenga (2013) para a compreensão e esclarecimento do nosso posicionamento a respeito do reconhecimento do trabalho artístico por intermédio do julgamento da beleza. Embora Lima (2009) afirme ser possível relacionar os julgamentos emitidos pelo público de teatro ao julgamento estético, admite as limitações deste julgamento, tendo em vista que o público, de modo geral, não conhece a fundo todo o trabalho e preparação realizados pelo ator desde a concepção até a apresentação de uma peça. Alvarenga (2013), referindo-se à atividade do músico de orquestra, admite igualmente a avaliação do belo, além da utilidade, pelo público, mas afirma haver maior reconhecimento da utilidade do trabalho do músico do que da sua beleza.

Nesse sentido, com base no referencial teórico adotado neste estudo e no caso empírico analisado, não consideramos o público expectador como emissor de julgamento estético no contexto da arte, por não possuir, ordinariamente, a compreensão técnica e cotidiana do saber fazer que envolve a criação artística. Salientamos que Equilibrista não vislumbra no público que assiste às suas apresentações a compreensão integral do seu trabalho. A artista revela explicitamente atribuir, neste sentido, maior relevância ao reconhecimento do seu trabalho quando proveniente de outros artistas que conhecem o ofício e sua trajetória neste campo.

Em um trabalho cujo resultado perpassa a experiência estética, a apreciação da obra e o reconhecimento do belo podem estar relacionados à satisfação dos desejos ou necessidades daqueles que com elas se deleitam, e não necessariamente à compreensão do saber fazer que as envolvem. Tal circunstância é corroborada por Baudrillard (2003) ao argumentar que, como bem de consumo, a cultura é experienciada não pelo valor de uso, mas pelo valor de troca ou diferenciação social. $\mathrm{O}$ autor desenvolve, ainda, argumentos acerca do processo de socialização para se tornar um consumidor de cultura. Sem desprezar a possibilidade de existência de uma formação cultural autêntica, Baudrillard (2003) defende que na sociedade de consumo, tende a ocorrer uma pseudoformação, considerando-se que a relação promovida entre os cidadãos e os bens culturais é destituída de uma vivência autêntica.

O primeiro contato de Equilibrista com o mundo artístico ilustra a relação utilitária. A inserção de Equilibrista na dança deu-se por indicação médica, como uma possibilidade de auxiliar na melhoria de uma condição física. Assim como com Equilibrista quanto criança, muitos de seus alunos infanto-juvenis começaram a dançar por influência dos pais, motivados por algum fator externo à experimentação da arte em si.

Conforme o relato de Equilibrista, alguns pais de seus alunos esperam que a dança contribua no desenvolvimento da capacidade de seus filhos se expressarem, outros esperam que auxilie na melhoria da coordenação motora, autoestima e capacidade de memorização. Todavia, assim como ocorreu com Equilibrista, quando as motivações que conduziram tais crianças e adolescentes à dança são satisfeitas, frequentemente, há por parte dos pais uma repetição do discurso de que a dança deve ser vista apenas como lazer, de que não deve tomar muito tempo e que não deve ser encarada como uma possibilidade de trabalho. 
Tal modo de consumir a cultura pode ser relacionado com o que Baudrillard (2003) denomina como M. C. C. (Menor Cultura Comum). A M. C. C. é associada ao menor conjunto de signos - panóplia - que alguém deve possuir para ser considerado um cidadão da sociedade de consumo e obter o título que cidadania cultural. Nessa conjuntura, o consumo cultural é vislumbrado como processo de classificação e diferenciação social. Conforme Baudrillard (2003, p.112113), o consumo cultural ocorre na medida em que o conteúdo da cultura "não alimenta a prática autônoma, mas a retórica de mobilidade social". Circunstância em que se busca um objeto diferente da cultura, visando-a como um simples elemento codificado de estatuto social - opera-se aqui uma inversão, e o conteúdo genuíno da cultura aparece somente como função e conotação secundária. Isto reforça o argumento de que os consumidores culturais tendem a proferir julgamentos da utilidade em relação ao trabalho artístico, em detrimento da apreciação estética.

Na perspectiva de Baudrillard (2003), o consumo é uma atividade sistemática de manipulação de significados com uma ênfase maior na expressividade que em seus aspectos funcionais, tendo valor enquanto interage com o mundo em que existe e significa algo. Já a mercadoria é o próprio significado, existe se houver significado a ser consumido, um significado à vista dos outros. Assim, Equilibrista, na sociedade de consumo tende a ser considerada ao mesmo tempo, produto/mercadoria e produtora, e como tal, a partir do julgamento da utilidade, seu trabalho é reconhecido enquanto tiver significado para os outros sujeitos. Frisamos que, de modo oposto aos produtos tangíveis, na dança, produto/mercadoria e produtor estão presentes e ambos tendem a ser encarados como um signo.

Todavia, há algumas ressalvas a serem feitas no que concerne a tal reconhecimento e ao julgamento da utilidade. A partir do princípio de que o julgamento da utilidade diz respeito à utilidade técnica, econômica e/ou social do trabalho realizado - conferindo ao trabalhador sua afirmação na esfera do trabalho -, cabe mencionar que para Equilibrista parece haver, na sua realidade, uma tendência de não compreensão do fazer artístico como um trabalho. Nas palavras de Equilibrista:

\footnotetext{
Por muito tempo até meus pais, por eu dançar desde pequena, desde os cinco anos, eles sempre falavam, (...) "a dança é só um hobby". (...). E tem muito, ainda hoje, essa dificuldade de se ver a arte, a dança, como um trabalho mesmo. Até os pais de alunos meus quando sabem que eu faço arquitetura, eles falam, "é, tem que ter alguma outra coisa, não dá para ficar só na dança e tal”. (Equilibrista).
}

\begin{abstract}
Eu falo para os professores da universidade, que eu trabalho com dança e por isso eu vou ter que faltar a próxima aula, eles falam: "tu vais lá dançar". (...). Realmente o nosso trabalho, não é visto como algo que tenha valor por ser algo prazeroso, e é um trabalho tanto quanto é outro trabalho (Equilibrista).
\end{abstract}

O relato da dançarina revela a prevalência de uma concepção de trabalho associada ao esforço laboral sistemático, executado mediante recompensa financeira. Como diria Freud ([1930]2011), nem todos observam o potencial sublimatório que uma atividade profissional possui, circunstância que dificulta a percepção do trabalho como uma via de satisfação. Assim, quando se observa a atividade artística como uma atividade profissional com alto potencial sublimatório, ou uma efetiva possibilidade de se vivenciar prazer, parece haver uma tendência à negação de que tal atividade possa ser considerada laboral.

Além de não ser percebida como uma possibilidade de se vivenciar prazer ou como uma fonte de satisfação, inúmeras pessoas percebem o trabalho como um emprego ou atividade que proporciona retorno financeiro ao sujeito. O acesso ao emprego, por sua vez, acaba sendo compreendido como uma forma de inserção social e uma condição de obtenção de certos direitos, incluindo-se o direito à proteção social e auxilio doença (DEJOURS, 2004a).

Ao refletir a respeito desta situação, percebemos um afastamento da realidade enfrentada pelos artistas. Nesse sentido, acreditamos que a ausência de vínculos formais de trabalho, a inexistência ou pouca presença de benefícios trabalhistas assegurados pela CLT e a instabilidade financeira que permeiam a carreira do artista são aspectos que também podem contribuir para a não compreensão por parte da sociedade do fazer artístico como um trabalho, e para a vivência de sofrimento por parte dos entrevistados. Tais circunstâncias divergem do entendimento de uma profissão demarcada, regular, sistemática e metódica relacionada ao ethos capitalista (WEBER, 2013).

Dejours (2012) admite o reconhecimento como elemento simbólico de realização da identidade cuja construção é mediada pelo trabalho. Neste sentido, a não compreensão da atividade artística enquanto trabalho, além de ser associada à vivência de sofrimento, pode ter um efeito deletério na saúde psíquica do trabalhador, bem como na constituição de sua identidade. Desde a infância, como afirma Gaulejac (2014), cada sujeito é educado com o objetivo de tornar-se 
um ser empregável. Não compreender a atividade artística enquanto trabalho é não reconhecer o artista enquanto trabalhador e tal relação não permanece neutra no que concerne à saúde mental de tais profissionais.

\section{Reflexões Finais}

Cientes das limitações em termos de estudos a respeito do trabalho artístico, principalmente no que se refere às questões relativas ao seu reconhecimento na sociedade de consumo, buscamos nesta investigação, discutir e analisar as possíveis relações existentes entre o consumo cultural e a dinâmica do reconhecimento do trabalho artístico. Para tal feito, realizamos uma aproximação entre a psicodinâmica do trabalho, o pensamento de Baudrillard (2003) e discussões concernentes ao trabalho artístico. Utilizamos o caso de Equilibrista como exemplo empírico do trabalho no contexto artístico, ilustrando a argumentação desenvolvida.

Com o intuito de atendermos ao objetivo deste estudo, partimos da premissa de que o trabalho artístico não passa incólume ao processo de homogeneização social. Conforme elucida Baudrillard (2003), a arte está, assim, inserida na mesma lógica dos demais objetos e é também apropriada enquanto bem de consumo. A obra e o fazer artístico guardam, no entanto, especificidades que fazem sua inserção na sociedade ocidental-capitalista contemporânea produzir consequências ainda mais perversas - especialmente nocivas aos trabalhadores deste campo.

Relembramos que na perspectiva dejouriana, o reconhecimento não é simples gratificação, e para ter eficiência simbólica, passa por julgamentos. O julgamento por sua vez, assume duas formas: o julgamento da beleza e o julgamento da utilidade (LIMA, 2013; DEJOURS, 2012). A apreciação quanto à beleza, que diz respeito à qualidade do trabalho, é expressa, sobretudo, em termos principalmente estéticos (DEJOURS, 2012). O julgamento de utilidade diz respeito à utilidade econômica, técnica e/ou social do trabalho realizado (de maneira singular e coletiva), conferindo ao trabalhador sua afirmação na esfera do trabalho.

Isto posto, como principais contribuições desta pesquisa, reconhecemos a predominância de pelo menos dois elementos, inter-relacionados e não exaustivos, que contribuem para uma não compreensão do trabalho artístico nas sociedades de consumo: a) a ascensão de um modo limitado de julgamento da utilidade, que dificulta o reconhecimento social do fazer artístico enquanto trabalho; e, b) a inibição do julgamento da beleza provocada pelo ethos competitivo do modo de produção capitalista.
Observamos que o distanciamento da vivência cultural como uma experiência autêntica tende a influenciar negativamente em sua dinâmica. Uma vez que a criação artística passa a ser inserida na lógica de consumo e desenvolvida, em inúmeras vezes, em função de tal lógica (BAUDRILLARD, 2003), dificulta-se o julgamento da beleza e promove-se o julgamento da utilidade do trabalho artístico. Julgamento este, que ocorre de modo limitado, tendo em vista o questionamento da utilidade técnica, econômica e social da atividade artística nas sociedades atuais.

A noção restrita do julgamento da utilidade tem como consequência o não reconhecimento social do fazer artístico enquanto trabalho. Circunstância que, segundo percebido no caso de Equilibrista, está relacionada ao fato de o trabalho artístico afastar-se da ideia convencional (dominante) de trabalho nas sociedades de consumo, associada ao esforço laboral executado mediante recompensa financeira por vínculo empregatício, preferencialmente formal; ao exercício de uma profissão demarcada, regular e sistemática relacionada ao ethos capitalista (DEJOURS, 2004a; WEBER, 2013). Ademais, salientamos que o não reconhecimento do fazer enquanto trabalho implica no não reconhecimento do sujeito fazedor enquanto trabalhador, e na deslegitimação social - em uma sociedade em que a inscrição social tende a ser determinada pela inserção no mercado de trabalho.

No que concerne ao julgamento da beleza, observamos que a configuração de um cenário competitivo dificulta o reconhecimento por intermédio de tal julgamento. Fato que tende a tolher a existência de relações de cooperação, manutenção de um espaço de discussão, bem como a inibir a legitimação de ações referentes ao uso da inteligência prática entre artistas de diferentes grupos.

Consideramos que a identificação dos dois movimentos contemporâneos relacionados ao julgamento da beleza e da utilidade na sociedade do consumo, anteriormente mencionados, contribui fundamentalmente em dois aspectos, a saber: na compreensão de condições de trabalho que envolvem o fazer artístico e das consequências para o sujeito em termos de identidade, prazer e sofrimento no trabalho; e, em uma perspectiva teórica, tendo em vista que ao realizarmos uma aproximação entre "A Sociedade de Consumo" de Baudrillard (2003) e o processo psicodinâmico de reconhecimento do trabalho (DEJOURS, 2012), evidenciamos elementos determinantes no processo psicodinâmico de reconhecimento do trabalho artístico na sociedade do consumo. Acreditamos ainda, que tais elementos se façam presentes em outras atividades de trabalho que se afastem da ideia convencional de trabalho relacionada ao ethos capitalista. 
Por fim, advertimos que o anseio não atendido pelo reconhecimento do trabalho desenvolvido é nocivo para a subjetividade do trabalhador e constituição da sua identidade. Sublinhamos, a partir de Dejours (2012), que tal situação pode implicar na não subversão do sofrimento em prazer, viabilizando o surgimento de uma crise de identidade ou de outras patologias. Nesse sentido, destacamos o papel do Estado na criação, implementação e na garantia da continuidade de políticas públicas voltadas ao financiamento de atividades e dispositivos culturais, e promoção do trabalho artístico. Acreditamos que na medida em que o Estado diminui sua atuação no fomento à cultura e uma promove uma maior participação do capital privado, corre-se o risco de as atividades culturais serem direcionadas a atenderem às demandas daqueles que as financiam (SEGNINI, 2014). Situação que pode tolher as possibilidades de vivências culturais autênticas do público, conforme já mencionado, e a dificultar o reconhecimento do trabalho artístico.

\section{Referências}

ALVARENGA, E. C. A Coragem de ser Músico de Orquestra Sinfônica: uma análise baseada na psicodinâmica do trabalho. 2013. Dissertação (Mestrado em Psicologia) - 2013. 101 f. Universidade Federal do Pará, Belém, 2013.

BAUDRILLARD, J. A Sociedade de Consumo. Lisboa: Edições 70, 2003.

BENDASSOLI, P. F. Significado do Trabalho e

Carreira Artística. FGV. Rio de Janeiro, p. 44. 2009.

BENHAMOU, F. A economia da cultura. São Paulo: Ateliê Editorial, 2007.

DEJOURS, J. C. Activisme professionnel: masochisme, compulsivité ou aliénation? Travailler, no 11, p. 25-40, 2004a.

DEJOURS, J. C. Subjetividade, trabalho e ação. Revista de Produção. São Paulo, Universidade de São Paulo, v.14, n.3 pp. 27-34, Set/dez. 2004b.

DEJOURS, J. C. Trabalho vivo: Trabalho e Emancipação (Tomo II). Brasília: Paralelo 15, 2012.

FREUD, S. O Mal-Estar na Civilização [1930]. São Paulo: Penguin Clasics Companhia das Letras, 2011.

DUMAS, Alexandre. A Mulher da Gargantilha de Veludo e outras Histórias de Terror. Rio de Janeiro: Zahar, 2012.
FACAS, E. P; SILVA, L. M. da; ARAÚJO, M. A.S.

Trabalhar. In: VIEIRA, F. de O.; MENDES, A. M.; MERLO, A. R. C. (Orgs.). Dicionário crítico de gestão e psicodinâmica do trabalho. Curitiba: Juruá, 2013. p. 461- 465.

\section{FUNDAÇÃO GETÚLIO VARGAS (FGV). A cultura} na Economia Brasileira. Rio de Janeiro: FGV, 2015.

GAULEJAC, V. de. Gestão como Doença Social: Ideologia, poder gerencialista e fragmentação social. São Paulo: Ideias \& Letras, 2014.

GERNET, I.; DEJOURS, C. Avaliação do trabalho e reconhecimento. In: BENDASSOLI, P. F.; SOBOLL, L. A. (Orgs.). Clínicas do Trabalho. São Paulo: Atlas, 2011. p. 61-70.

LIMA S. C. C. Reconhecimento no Trabalho. In: VIEIRA, F. de O.; MENDES, A. M.; MERLO, A. R. C. (Orgs.). Dicionário crítico de gestão e psicodinâmica do trabalho. Curitiba: Juruá, 2013. p. 351-355.

LIMA, V. S. Vida de Artista: Análise Psicodinâmica do Prazer e do enfrentamento do sofrimento em um grupo de comediantes do DF. 2009. Dissertação (Mestrado em Psicologia Social) - 2009. 185 f. Universidade de Brasília, Brasília, 2009.

LOACKER, B. Becoming 'culturpreneur': How the 'neoliberal regime of truth' affects and redefines artistic subject positions. Culture and Organization, AbingdonUK, v. 19, n. 2, p. 124-145, 2013.

MARTINS, S. R.; LIMA, S. C. C. Reconhecimento e Coletivo de Trabalho. In: MONTEIRO, J. K; VIEIRA, F. O.; MENDES, A. M. (Orgs). Trabalho e Prazer: teoria, pesquisas e práticas. Curitiba: Juruá, 2011. p. 51-74.

MENDES, A. M. (Org.). Psicodinâmica do trabalho: teoria, método e pesquisas. São Paulo: Casa do Psicólogo, 2007.

MENDES, A. M.; DUARTE, F. S. Mobilização subjetiva. In: VIEIRA, F. de O.; MENDES, A. M.; MERLO, A. R. C. (Orgs.). Dicionário crítico de gestão e psicodinâmica do trabalho. Curitiba: Juruá, 2013. p. 259- 262.

MENGER, P.-M. Artists as Workers: Theoretical and methodological challenges. Poetics, 28, 2001, p. 1-19.

MENGER, P-M. Retrato do artista enquanto trabalhador: metamorfose do Capitalismo. Lisboa: Editora Roma, 2005. 
MONTEIRO, J. K.; MORAES, R. D.; MENDES, A. M.; MERLO, A. R. C. Psicodinâmica do Trabalho no

Brasil: práticas, avanços e desafios. Curitiba: Juruá, 2017.

SANT'ANNA, A., de S. Cooperação. In: VIEIRA, F. de O.; MENDES, A. M.; MERLO, A. R. C. (Org.).

Dicionário crítico de gestão e psicodinâmica do trabalho. Curitiba: Juruá, 2013. p. 98-102.

SANTOS, T. C. A sociedade de consumo, os media e a comunicação nas obras iniciais de Jean Baudrillard.

Revista Galáxia, São Paulo, n. 21, p. 125-136, jun. 2011.

Mendes 2007 b

SEGNINI, L. R. P. Os músicos e seu trabalho: Diferenças de gênero e raça. Tempo Social, São Paulo, v. 26, n. 1, p. 75-86, june 2014. Disponível em: <http:/ /www.revistas. usp.br/ts/article/view/84980>. Acesso em: 14 mar. 2018.

SEGNINI, M.P. Prazer e sofrimento no trabalho artístico em dança. 2010. 156 p. Dissertação (mestrado em Ciências da Reabilitação) Faculdade de Medicina da Universidade de São Paulo. São Paulo. 2010.

THROSBY, D. Defining the artistic workforce: the Australian experience. Poetics, 28, p. 255-271, 2001.

VASCONCELOS, A. C. L. Inteligência Prática In: VIEIRA, F. de O.; MENDES, A. M.; MERLO, A. R. C. (Orgs.). Dicionário crítico de gestão e psicodinâmica do trabalho. Curitiba: Juruá, 2013. p. 237 - 242.

WEBER, M. A Ética protestante e o Espírito do Capitalismo [1904]. 1. ed. São Paulo: Martin Claret, 2013. 